\title{
PENERAPAN METODE SIMPLE ADDITIVE WEIGHTING (SAW) DALAM SISTEM PENGAMBILAN KEPUTUSAN ORDER PERSEDIAAN BARANG BERBASIS WEB
}

\author{
Iin Marliana \\ marlyna@umitra.ac.id \\ Universitas Mitra Indonesia
}

\begin{abstract}
Nowaday, computers already can be used to provide choices in taking of the decision, not only used for data processing or presenting information, process of taking the decision it self is the results of a system that called Sistem Pendukung Keputusan (SPK). The system of taking the decision is possible because there has been a development of hardware technology, integration of hardware and software. In the business sector one of them is a truck and expedition which engages in the transportation services of stuffs between Lampung-Surabaya cities and vice versa. In this expedition service consists of arround used by 76 units of cars. And the supply of stuffs still used bookkeeping which is sometimes taking of the decision supply of stuffs is still handled by superiors.

Therefore, this research used Simple Additive Weighting (SAW) method which is used to make decisions in problems solving by create a design system and building software. This research will create a system when taking the decision in the supply of stuffs in the Business Entity Expedition Services with SAW method by using WEB.
\end{abstract}

Keyword: SPK, SAW and WEB

\begin{abstract}
Abstrak: Penggunaan komputer sekarang ini sudah dapat digunakan untuk memberikan pilihan dalam hal pengambil keputusan, bukan hanya sekedar melakukan pengolahan data ataupun penyajian informasi, Proses pengambilan keputusan tersebut dari hasil sitem yang dinamakanSisitem Pendukung Keputusan (SPK). System pengambil keputusan dimungkinkan karena telah terjadi perkembangan teknologi hardware, dan integrasi dari perangkat keras, perangkat lunak.Dalam bidang usaha salah satunya adalah ekspedisi truk dan engkel yang bergerak dalam hal jasa angkutan barang antar kota Lampung-Surabaya dan sebaliknya. Pada Jasa ekspedisi ini terdiri dari sekitar 76 unit mobil yang digunakan. Dan dalam persediaan barangnya masih menggunakan pembukuan yang terkadang keputusan pengambilan persediaan barangnya masih ditangani oleh atasan.

Pada penellitian ini digunakan Metode Simple Additive Weighting (SAW) yang digunakan untuk mengambil keputusan dalam pemecahan masalah dengan membuat rancangan sistem dan membangun perangkat lunak. Penelitian ini akan membuat suatu sistem pengambilan keputusan dalam persediaan barang pada Badan Usaha Bidang Jasa Ekspedisi dengan menggunakan metode SAW berbasis WEB.
\end{abstract}

Kata Kunci : SPK, SAW dan WEB.

\section{PENDAHULUAN}

Penggunaan komputer sekarang ini sudah dapat digunakan untuk memberikan pilihan dalam hal pengambil keputusan, bukan hanya sekedar melakukan pengolahan data ataupun penyajian informasi, Proses 
pengambilan keputusan tersebut dari hasil sitem yang dinamakanSisitem Pendukung Keputusan (SPK). System pengambil keputusan dimungkinkan karena telah terjadi perkembangan teknologi hardware, dan integrasi dari perangkat keras, perangkat lunak.

Dalam menentukan order persediaan barang dilakukan dengan cara menyeleksi para calon pemenang proyek yang mana dalam penyeleksian order persediaan barang, masih terdapat kesalahan seperti kesalahan dalam penyeleksian kriteriakriteria calon pemenang proyek. Dalam penentuan pemenang proyek diperlukan suatu sistem yang tekomputerisasi untuk mempermudah peroses pengadaan barang dan jasa. Pada sistem kegiatan pelaksanaan proyek order persediaan barang untuk menghasilkan pemenang diperlukan pendukung keputusan, dan pada akhirnya proyek dapat dilakukan sesuai dengan kebijakan yang ada.

Adapun masalah yang dapat diidentifikasi adalah :

1. Penentuan keputusan order persediaan barang.

2. Keputusan order persediaan barang, yang diberikan sebagai penunjang pengambil keputusan.

Perumusan masalah dalam penelitian ini adalah : "Bagaimana membuat sistem pendukung pengambilan keputusan dalam melakukan penyeleksian order persediaan barang?"

Adapun tujuan dari penelitian mengenai perencanaan distribusi :

a. Penyeleksian order persediaan barang untuk menghasilkan pemenang dari proyek.

b. Pemecahan suatu masalah dengan membuat rancangan sistem dan membangun perangkat lunak.

\section{METODE}

\section{a. Sistem Pengambilan Keputusan}

Sistem pengambilan keputusan pada penelitian ini dibuat untuk penentuan order persediaan barang pada proses pengadaan barang dan jasa. Sistem ini dibuat untuk membantu panitia pengadaan barang dan jasa bagaimana seharusnya keputusan itu dipilih.

\section{b. Metode Penyelesain Masalah}

Pada penelitian ini menggunakan Metode SAW atau metode penjumlahan terbobot. Metode SAW membutuhkan normalisasi matriks keputusan

Keterangan :

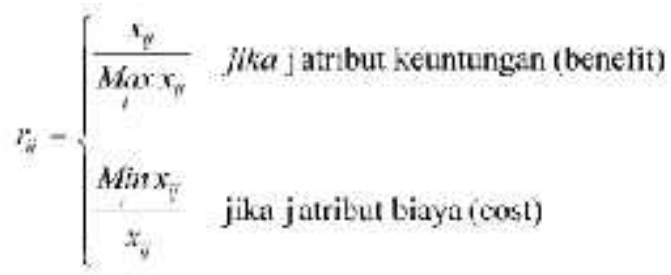


Dimana $T_{l}$ adalah nilai rating kinerja ternormalisasi, $x_{l}$ adalah nilai atribut yang dimiliki dari setiap kriteria, Max $x_{l} \quad$ adalah nilai terbesar dari setiap kriteria, $i$

Min $X_{l} \quad$ adalah nilai terkecil dari setiap kriteria $\quad \boldsymbol{i}$ benefit adalah jika nilai terbesar adalah terbaik dan cost adalah jika nilai terkecil adalah terbaik

$\Gamma_{l}$ adalah rating kinerja ternormalisasi dari alternatif $A_{l}$ pada atribut $C_{j} ; \mathrm{i}=1,2, \ldots, \mathrm{m}$ dan $\mathrm{j}=1,2, \ldots$, n.Nilai preferensi untuk setiap alternatif $\left(V_{\ell}\right)$ diberikan

$$
\boldsymbol{V}_{i}=\sum_{j=1}^{n} \boldsymbol{W}_{j} \boldsymbol{r}_{i j}
$$

\section{Keterangan :}

$V_{i}$ adalah ranking untuk setiap alternatif, $W_{j}$ adalah nilai bobot dari setiap kriteria, $\Gamma_{l}$ adalah nilai rating kinerja ternormalisasi

Dan nilai $V_{l}$ yang lebih besar mengindikasikan bahwa alternatif $A_{i}$ lebih terpilih.

\section{c. Basis Data}

Menurut James Martin (1975) yang dikutip dalam buku basis data dalam tinjauan konseptual, bahwa basis data adalah suatu kumpulan data yang terhubung dan disimpan secara bersama-sama pada suatu media, dan haru miminimalisir kerangkapan data yang disimpan. Data yang disimpan dapat digunakan kembali oleh satu atau lebih program aplikasi, untuk mempermudah pemeroean dan pengontrolan data haru disimpan sedemikian rupa.

\section{d. Macromedia}

Dreamweaver adalah salah satu software dari kelompok Macromedia yang banyak digunakan untuk merancang dan mendesain situs web menurut (MADCOMS, 2007:1). Adapun Macromedia Dreamweaver itu sendiri adalah sebuah HTML editor profesional yang dapat digunakan untuk mendesain dan mengelola situs web maupun halaman web. Pada penelitian ini menggunakan Dreamweaver 8 karna pada aat penelitian ini dilakukan merupakan very yang terbaru dan memiliki performa yang baik.

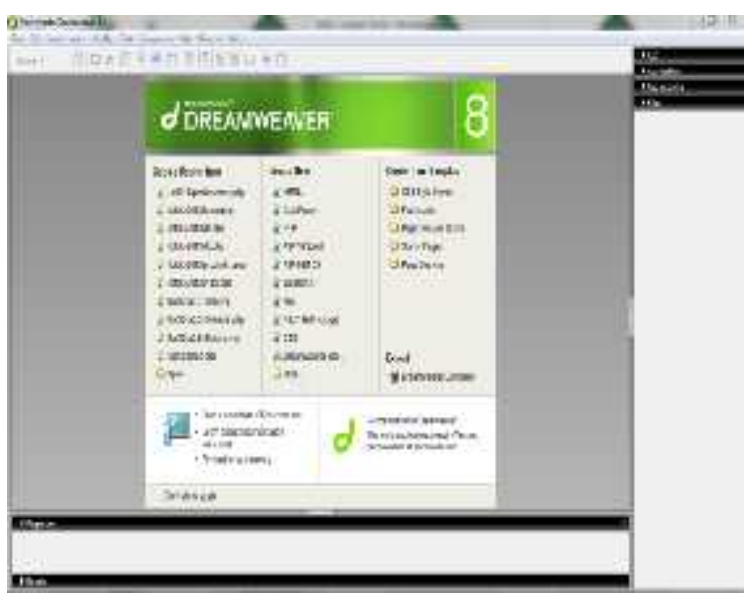

tampilan awal dari dreamwever 8.0. 


\section{e. Air Terjun (Waterfall)}

Untuk mengembangkan perangkat lunak dalam penelitian ini juga menggunakan metode Waterfall

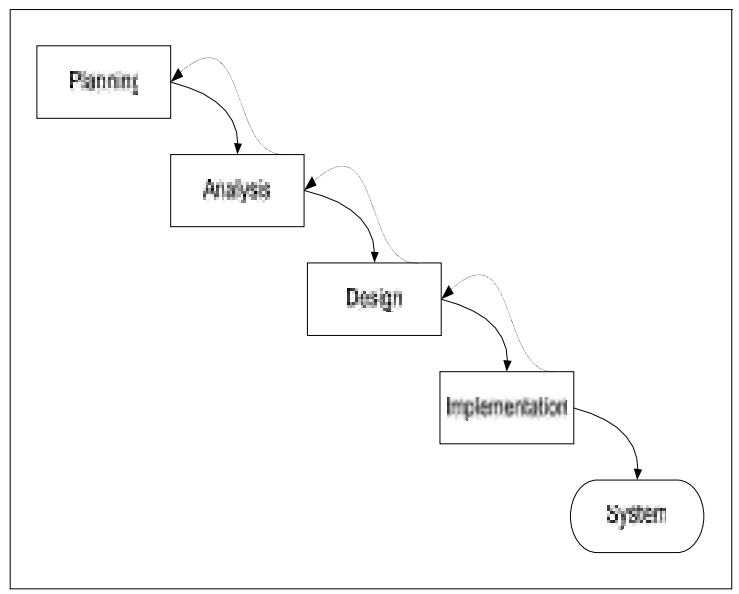

Metode Waterfall

\section{HASIL DAN PEMBAHASAN}

Rekayasa perangkat lunak yang dilakukan pada penelitian ini adalah dimana proses nya disebut dengan analisa perhitungan metode SAW dan diimplementasikan sebagai berikut :

\section{A. Analis}

Dalam tahap ini akan dijelaskan dan diuraikan rancangan prosedur tentang proses pemasukan data dari admin pada sistem sampai proses penyeleksian calon pemenang proyek yang dilakukan pada sistem tersebut.

Pada rancangan prosedur pengembangan sistem penyeleksian proyek pengadaan barang ini di deskripsikan sebagai berikut :

a. Untuk mengakses aplikasi ini admin melakukan input username dan password yang sesuai pada sistem, hal ini dilakukan untuk meng-update dan menginput data yang ada.

b. Ketika user name sesuai maka admin wajib melakukan proses terhadap sistem pengolahan data peerta proyek dan apabila sudah tidak ada lagi aktifitas dalam sistem, admin diwajibkan untuk log out

\section{B. Analisa Perhitungan Metode SAW}

Pada sistem ini penyeleksian proyek pengadaan barang untuk mendapatkan pemenang proyek menggunakan metode SAW, adapun urutan yang dilakukan dalam penentukan pemenang proyek adalah:

1. Menentukan kriteria yang digunakan, adapun kriteria tersebut sebagai berikut:

$\mathrm{C} 1=$ Pembukaan Penawaran

C2=Harga Penawaran

C3=Harga Penawaran Terkoreksi

C4=Surat Idzin Usaha

C5=Neraca Perusahaan

C6=Laporan Pajak

C7=Identitas Barang

C8=Spesifikasi Teknis

C9=Dukungan Agen

C10=Jaminan Purna Jual

2. Mecocokan setiap alternatif pada setiap kriteria, dinilai dengan nilai antara 1 sampai 5 berdasarkan ratingnya yaitu : 

a. 1 = Sangat Buruk
b. $2=$ Buruk
c. $3=$ Cukup
d. 4 = Baik
e. 5 = Sangat Baik

3. Menentukannilai setiap kreteria berdaarkan tingkat kepentingan dengan nilai 1 sampai 5 yaitu :

1 sama dengan Sangat Rendah, 2 sama dengan Rendah, 3 sama dengan Cukup, 4 sama dengan Tinggi dan 5 sama dengan Sangat Tinggi

4. Menentukkan bobot preferensi Adapun penetuan dari bobot preferensi setiap kriteria penilaian proyek adalah sebagai berikut :

$$
\mathrm{W}=(5,5,5,5,5,5,5,5,5,5)
$$

Jika rating kecocokan, kepentingan kriteria, bobot preferensi telah ditentukan maka penilaian proyek dapat di hitung.

Tabel 5.1 Rating Kecocokan Setiap Perusahaan pada setiap Kriteria

\begin{tabular}{|l|l|l|l|l|l|l|l|l|l|l|}
\hline \multirow{2}{*}{$\begin{array}{l}\text { Perusaha } \\
\text { an }\end{array}$} & \multicolumn{10}{|c|}{ Kriteria } \\
\cline { 2 - 10 } & 1 & 2 & 3 & 4 & 5 & 6 & 7 & 8 & 9 & 0 \\
\hline $\begin{array}{l}\text { PT. } \\
\text { Ranko } \\
\text { Sagothar }\end{array}$ & 5 & 4 & 3 & 5 & 5 & 5 & 5 & 5 & 5 & 5 \\
\hline $\begin{array}{l}\text { Cv Silvia } \\
\text { Patria }\end{array}$ & 5 & 4 & 5 & 5 & 4 & 5 & 5 & 4 & 5 & 4 \\
\hline PT. & 5 & 5 & 5 & 4 & 4 & 4 & 5 & 4 & 4 & 4 \\
\hline
\end{tabular}

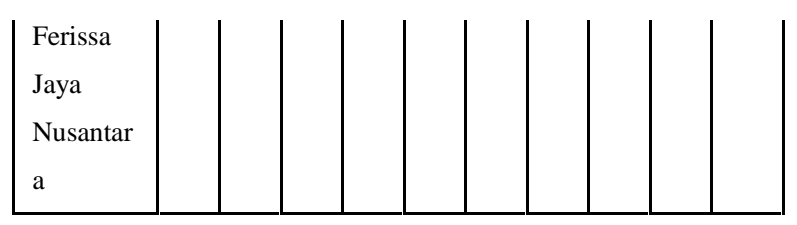

berdasarkan tabel kecocokan maka dibuat matriks keputusan sebagai berikut :

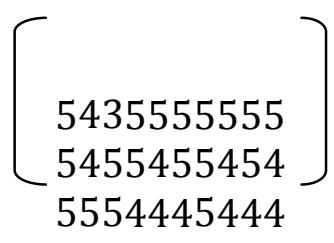

Pertama-tama, lakukan normalisasi matriks keputusan sebagai berikut :

$$
\begin{aligned}
& R_{11}=\frac{5}{\operatorname{Max}\{5 ; 5 ; 5\}}=\frac{5}{5}=1 \\
& R_{21}=\frac{5}{\operatorname{Max}\{5 ; 5 ; 5\}}=\frac{5}{5}=1
\end{aligned}
$$

$$
\begin{aligned}
& R_{31}=\frac{5}{\operatorname{Max}\{5 ; 5 ; 5\}}=\frac{5}{5}=1 \\
& R_{12}=\frac{4}{\operatorname{Max}\{4 ; 4 ; 5\}}=\frac{4}{5}=0,8 \\
& R_{22}=\frac{4}{\operatorname{Max}\{4 ; 4 ; 5\}}=\frac{4}{5}=0,8 \\
& R_{32}=\frac{5}{\operatorname{Max}\{4 ; 4 ; 5\}}=\frac{5}{5}=1 \\
& R_{13}=\frac{3}{\operatorname{Max}\{3 ; 3 ; 5\}}=\frac{3}{5}=0,6
\end{aligned}
$$




$$
\begin{aligned}
& n_{21}-\frac{1}{1+1 ; 1 ; 1}=\underline{y}=
\end{aligned}
$$

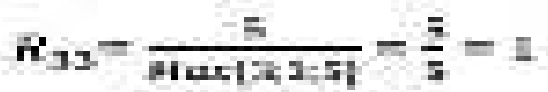

$$
\begin{aligned}
& \mathrm{n}_{1+}-\frac{5}{M+1 E-51}=\frac{5}{3}= \\
& n_{24}-\frac{2}{11+12 E_{11}}=\frac{5}{2}= \\
& n_{1+}-\frac{4}{1+1-5+1}=\frac{1}{5}-1
\end{aligned}
$$

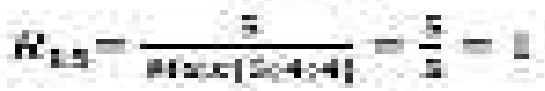

$$
\begin{aligned}
& n_{z=}-\frac{1}{|+|+1+4 \mid}=\frac{1}{2}=n
\end{aligned}
$$

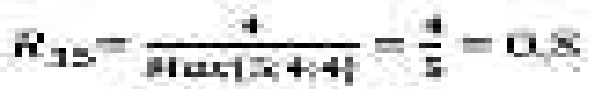

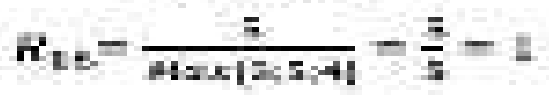

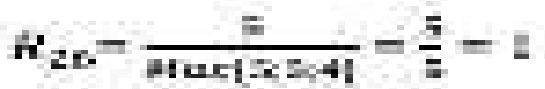

$$
\begin{aligned}
& n_{12}=\frac{1}{1 m-15+4}=\frac{1}{5}-13
\end{aligned}
$$

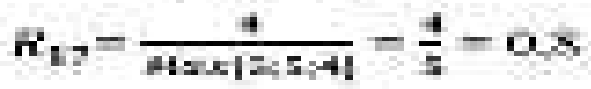

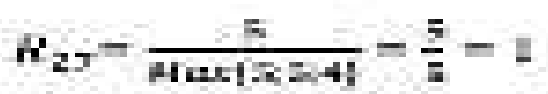

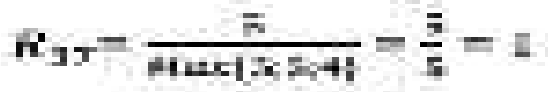

$$
\begin{aligned}
& n_{L=}=\frac{4}{m+14+1}=\frac{1}{4}=
\end{aligned}
$$

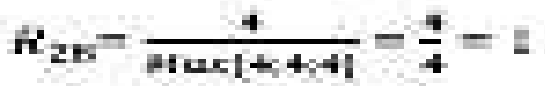

$$
\begin{aligned}
& r_{12}-\frac{1}{\mid m+1+4 !}=\frac{1}{4}=
\end{aligned}
$$

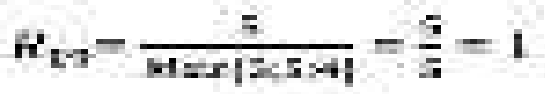

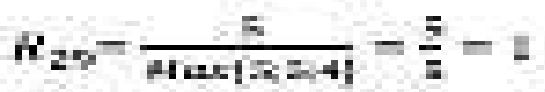

$$
\begin{aligned}
& r_{\mathrm{n}}-\frac{4}{-2-1}-4
\end{aligned}
$$

$$
\begin{aligned}
& R_{30}=\frac{4}{\operatorname{Mar}[5,4]}=\frac{4}{5}=0,8 \\
& R_{110}=\frac{4}{\operatorname{Max}[4,4]}=\frac{4}{4}=1 \\
& R_{210}=\frac{4}{\operatorname{Max}[4,4,4]}=\frac{4}{4}=1 \\
& R_{310}=\frac{4}{\operatorname{Max}[4,4 / 4]}=\frac{4}{4}=1
\end{aligned}
$$

Jadi matriks ternormalisasi $\mathrm{R}$ sebagai berikut :

$\left[\begin{array}{cccccccccc}1 & 0,8 & 0,6 & 1 & 1 & 1 & 0,8 & 1 & 1 & \\ 1 & 0,8 & 1 & 1 & 0,8 & 1 & 1 & 1 & 1 & 1 \\ 1 & 1 & 1 & 0,8 & 0,8 & 0,8 & 1 & 1 & 0,8 & 1\end{array}\right]$

Perankingan diperoleh berdasarkan perkalian antara matriks ternormalisasi $\mathrm{R}$ dan bobot preferensi (W x R) yaitu: ternormalisasi R sebagai berikut :

$$
\mathrm{W}=(5,5,5,5,5,5,5,5,5,5) \quad \mathrm{X}
$$

$\left[\begin{array}{cccccccccc}1 & 0,8 & 0,6 & 1 & 1 & 1 & 0,8 & 1 & 1 & 1 \\ 1 & 0,8 & 1 & 1 & 0,8 & 1 & 1 & 1 & 1 & 1 \\ 1 & 1 & 1 & 0,8 & 0,8 & 0,8 & 1 & 1 & 0,8 & 1\end{array}\right]$

Proses Perankingan diperoleh sebagai berikut

$$
\begin{aligned}
V_{1}= & (5 \times 1)+(5 \times 0.8)+(5 \times 0.6)+(5 \times \\
1)+ & (5 \times 1)+(5 \times 1)+(5 \times 0.8)+ \\
& (5 \times 1)+(5 \times 1)+(5 \times 1)=46 \\
V_{2}= & (5 \times 1)+(5 \times 0.8)+(5 \times 1)+(5 \times 1) \\
& +(5 \times 0.8)+(5 \times 1)+(5 \times 1)+ \\
& (5 \times 1)+(5 \times 1)+(5 \times 1)=48 \\
V_{3}= & (5 \times 1)+(5 \times 1)+(5 \times 1)+(5 \times 0,8) \\
& +(5 \times 0.8)+(5 \times 0.8)+(5 \times 1)+ \\
& (5 \times 1)+(5 \times 0.8)+(5 \times 1)=46
\end{aligned}
$$

Dari perhitungan diatas nilai terbesar adalah $V_{2}$ elanjutnya $A_{2}$ adalah alternatif yang terpilih sebagai alternatif terbaik. Artinya, CV Silvia Patria yang menjadi pemenang proyek. 


\section{c. Diagram Konteks}

Aliran data dalam system dapat digambarkan dengan diagram konteks sebagai berikut:

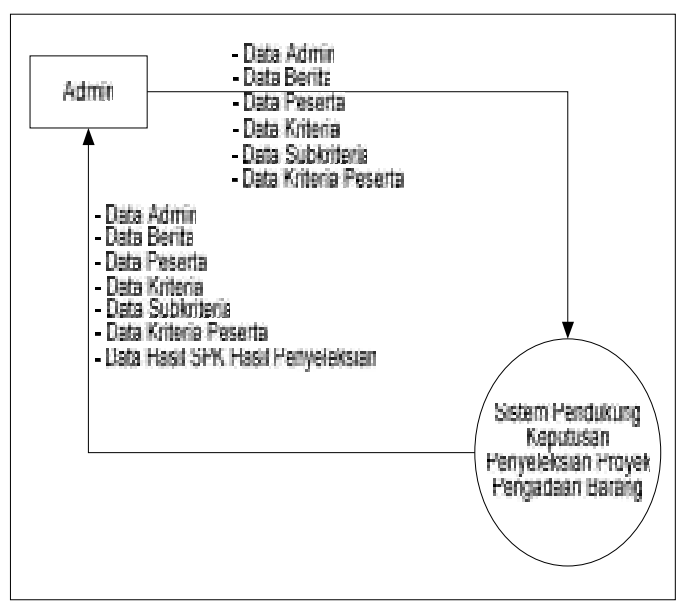

Gambar 4.2 Diagram Konteks

\section{d. Data Flow Diagram}

Aliran data dalam sistem secara rinci.

Dapat dilihat pada gambar Data Flow

Diagram dibawah ini :

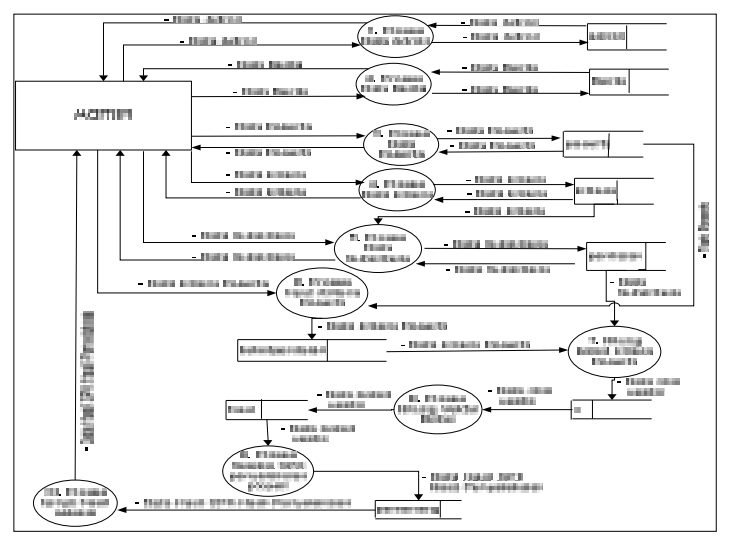

Gambar 4.3 Data Flow Diagram

\section{e. Relasi Table}

Istilah basis data adalah suatu kumpulan data yang terhubung dan disimpan dalam suatu secara bersama-sama, tanpa ada data gandaa (kalau ada data ganda maka data tersebut harus dapat terkontrol) data disimpan dengan caracara tertentu sehingga mudah digunakan atau ditampilkan kembali. Hubungan antar tabel ini direlasikan dengan relational key atau kunci utama dari masing-masing data pada file atau tabel. Pada gambar dibawah ini terlihat hubungan antar tabel :

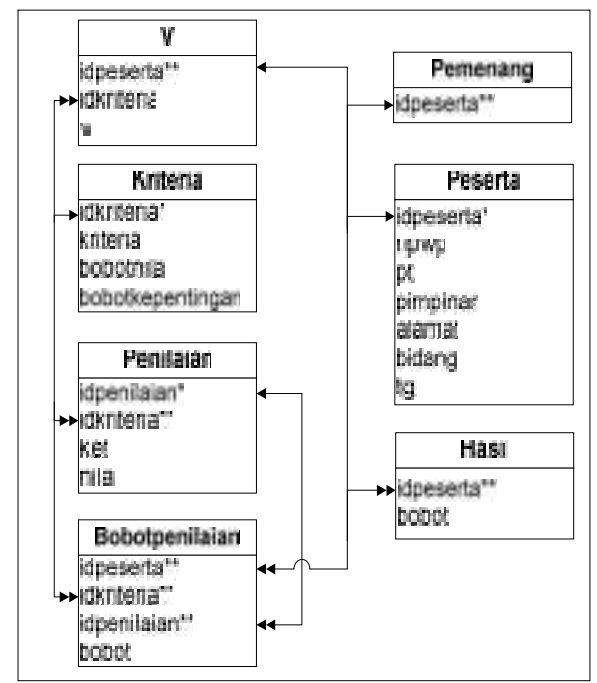

Gambar 4.4 Relasi Tabel

\section{f. Flowchart}

Flowchart adalah salah satu cara penggambaran alir dari sebuah program secara logika. Flowchart yang penulis buat dapat digambarkan sebagai berikut:

Flowchart Program Menu Admin 


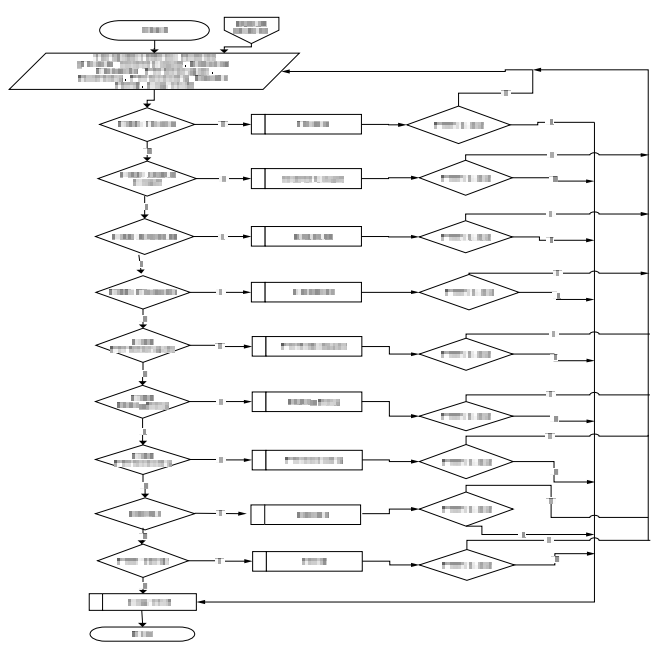

Sistem pengambilan keputusan dirancang untuk membangun sebuah situs, seperti diagram alur, tujuan, isi dari sebuah sistem. System SPK ini dibangun menggunakan PHP dan MySQL. Untuk membuat layout dari situs yang dirancang menggunakan Dreamweaver 8.0 Adapun halaman-halaman yang dirancang penulis, yaitu :

\section{SIMPULAN}

Dari hasil penelitian ini dapat disimpulkan sebagai berikut.

1. Dalam melakukan penyeleksian peserta proyek order persediaan barang masih terdapat kesalahan dalam penyeleksian kriteria-kriteria calon pemenang proyek.

2. Sistem yang diusulkan berdasarkan pada metodologi analisis desain terstruktur dimana setiap tahapan menguraikan secara detail SPK yang dibuat.

3. Sistem pendukung keputusan yang diusulkan memudahkan pegawai dalam proses penyeleksian peserta proyek pengadaan barang.

\section{Saran}

Berdasarkan kesimpulan yang telah diambil, saran dari penelitian ini sebagai berikut.

1. Sistem yang telah dibuat sebaiknya diterapkan dapat diterapkan untuk memudahkan proses penyeleksian peserta proyek pengadaan.

2. Sistem ini dapat dikembangkan lagi agar lebih lengkap dengan cara menambahkan fitur-fitur yang lain.

\section{DAFTAR PUSTAKA}

Darmastuti, Destriyana. (2013). Jurnal. Implementasi Metode Simple Additive Weighting (SAW) Dalam Sistem Informasi Lowongan Kerja Berbasis Web Untuk Rekomendasi Pencari Kerja Terbaik. 2013: 3)

Dennis, Alan. Barbara H Wixom. (2003). System Analysis Design $2^{\text {nd }}$ Edition. Jhon Wiley and Son. Inc United States of America.

Jogiyanto HM. (2005). Analisis \& Desain, Ed ke-III. Andi Offset : Yogyakarta. 
Komputer, Wahana. (2010). Panduan Belajar MySQL database server. Media Kita: Jakarta.

Kusrini, M.Kom. (2007). Konsep dan Aplikasi Sistem Pendukung Keputusan. Andi: Yogyakarta.

Kusumadewi, Sri, dkk. (200)6. Fuzzy Multi-Attribute Decision Making (Fuzzy MADM). Graha Ilmu: Yogyakarta.

Madcoms. 2007. Mahir Dalam 7 Hari Macromedia Dreamweaver 8 dengan PHP. Andi: Yogyakarta.

Peranginangin, Kasiman. 2006. Aplikasi Web dengan PHP dan MySQL. Andi: Yogyakarta.

Rudyanto, Arief, M. 2011. Pemrograman Web Dinamis menggunakan PHP dan MySQL. Andi: Yogyakarta.

Sakur, B, Stendy. 2005. Aplikasi Web Database dengan Dreamweaver MX 2004. Andi: Yogyakarta

Sutabri, Tata. 2005. Sistem Informasi Manajemen. Andi: Yogyakarta.

Sutanta, Edhy. 2011. Basis Data dalam (Tinjauan Konseptual). Andi: Yogyakarta.

Tantra, Rudy. 2012. Manajemen Proyek Sistem Informasi (Bagaimana Mengelola Proyek SI Secara Efektif dan Efisien). Andi: Yogyakart 